criter subrugose punctatis, apice singulatim rotundatis, callo humerali obsoleto; tarsis of o simplicibus. Long. 6-7 mm.

Von allen bekannten Arten der Untergattung Omophlina durch die hellen Schienen und Tarsen, sowie besonders durch die weisslichgraue, feine, anliegende Behaarung leicht zu unterscheiden. Manchmal sind auch die Fühler braun. Selten ist beim $q$ Kopf und Halsschild rothbraun.

Wurde von Herrn Eugen Willberg Ende April 1891 bei den Dörfern Icara-Dschida und Dyvana bei Margelan zahlreich gesammelt. Dem Entdecker zu Ehren benannt.

\title{
Coleopterologische Notizen.
}

Von Edmund Reitter in Paskau (Mähren).

$$
\text { XLIV.*) }
$$

363. Sphenoptera procera Reitt. Entom. Nachr. 1890, pag. 277 $=$ Sph. Potanini Jakowl. Horae Soc. Entom. Ross. 1889, pag. 86.

364. Anthaxia similis Saunders, Cat. Rupr. 1874, pag. $54=$ morio, Hrbst. und ist in diesem Sinne im Catal. Col. Eur. vom Jahre 1891 zu corrigiren.

365̃. Aomus (Schönh.) pubescens Bohem., aus Persien beschrieben, kommt bei Ordubad im Araxesthal (am Ahdagh) vor. Diese Gattung hat Aehnlichkeit mit Elytrodon und Pholicodes und ist bei letzterer zu placiren. Ich habe das Thier unter dem Namen Elytrodon biformis m. i. l. versendet.

366. Cephennium majus Reitt., aus Krain und Croatien, wurde von Herrn Brisout de Barneville zu laticolle Aubé gezogen. Herr Guillebeau macht auch darauf aufmerksam, dass diese Zusammenziehung ungerechtfertigt war, indem er mir gleichzeitig Exemplare des französischen C. laticolle einsandte welche dem majus wohl recht ähnlich, aber sicher von letzterem specifisch abgetrennt werden müssen. Das $C$. majus m. ist noch etwas grösser und gleichzeitig schlanker gebaut, die zwei vorletzten Fühlerglieder sind mehr quadratisch, der Halsschild ist an der Basis stärker eingezogen, die Flügeldecken vorn mehr gerundet erweitert, das Basalgrübchen viel kleiner, das Seitenfältchen feiner, mehr gebogen und mehr seitlich gelegen, von oben kaum wahrzunehmen; endlich ist die Behaarung länger und mehr emporgehoben.

*) XLIII. siehe Wien. Ent. Ztg. 1892, pag. 25. 


\section{$2 \mathrm{BHL}$ Biodiversity Heritage Library}

Reitter, Edmund. 1892. "Coleopterologische Notizen." Wiener entomologische Zeitung 11, 136. https://doi.org/10.5962/bhl.part.27706.

View This Item Online: https://www.biodiversitylibrary.org/item/44096

DOI: https://doi.org/10.5962/bhl.part.27706

Permalink: https://www.biodiversitylibrary.org/partpdf/27706

\section{Holding Institution}

Smithsonian Libraries

\section{Sponsored by}

Smithsonian

\section{Copyright \& Reuse}

Copyright Status: NOT_IN_COPYRIGHT

This document was created from content at the Biodiversity Heritage Library, the world's largest open access digital library for biodiversity literature and archives. Visit BHL at https://www.biodiversitylibrary.org. 